\title{
Clinical Management of Kidney Allograft Dysfunction
}

\author{
Rubin Zhang \\ Section of Nephrology, Department of Medicine, Tulane University School of Medicine, New Orleans, USA \\ Email: rzhang@tulane.edu
}

Received 28 February 2014; revised 28 March 2014; accepted 5 April 2014

Copyright (C) 2014 by author and Scientific Research Publishing Inc. This work is licensed under the Creative Commons Attribution International License (CC BY). http://creativecommons.org/licenses/by/4.0/

(c) (7) Open Access

\begin{abstract}
Allograft dysfunction is a common problem after kidney transplant. Allograft rejection is an important entity, and timely diagnosis and appropriate treatment are essential for caring transplant recipients. Hyperacute rejection is mediated by the preformed donor specific antibody, while accelerated acute rejection represents an anamnestic response by memory $B$ and $T$ cells. They occur early after transplant. Acute cellular rejection is relatively common and usually responds to pulse corticosteroids or antithymocyte globulin (ATG). The complexity of antibody-mediated rejection (AMR) as well as its detrimental effect has been increasingly recognized. The treatment of acute AMR requires a combination of several modalities, such as plasmapheresis or immunoadsorption, IVIG, corticosteroids, rituximab and ATG. After treatment of rejection episode, the maintenance immunosuppressive drugs should be adjusted to prevent further acute rejection and/or evolution into chronic active rejection. Chronic rejection is not reversible and it has been recognized as the most important cause of chronic graft dysfunction and failure.
\end{abstract}

\section{Keywords}

Acute Rejection, Cellular Rejection, Donor Specific Antibody, Antibody-Mediated Rejection, Chronic Rejection

\section{Introduction}

Kidney transplantation has become the preferred treatment for qualified patients with end stage of renal disease. Successful kidney transplant is more cost-effective than maintenance dialysis, and more importantly, it provides better quality of life and prolongs life [1]. Renal allograft dysfunction is a common and complex problem and appropriate management is critical for the long-term graft function and graft survival. The common causes of 
acute graft dysfunction are summarized in Table 1 . The clinical work-up is similar to acute kidney injury of native kidneys in both pre-renal and post-renal aspects. Additionally, there are several types of rejection that can occur in transplanted kidney, including hyperwacute rejection, accelerated acute rejection, acute rejection and chronic active rejection [2]-[5]. The advance in transplant immunology provides us the insight into the complexity of antibody-mediated rejection as well as its detrimental effects on the graft function and survival. The process of allograft rejection may evolve from pre- and/or post-transplant sensitization, to acute rejection or subclinical rejection, to chronic active rejection and to eventual graft failure. This review will discuss the work-up of graft dysfunction and particularly will focus on the clinical diagnosis and management of acute rejection.

\section{Hyperacute Rejection}

Hyperacute rejection occurs immediately after transplant. It is mediated by the preformed donor specific antibody (DSA). DSA can be anti-HLA, anti-ABO or other non-HLA antibodies [2]-[5]. Hyperacute rejection results in an irreversible vascular rejection, intravascular thrombosis and graft necrosis. The graft is tender and does not make much urine. Renal scan shows no or little uptake, which is different from acute tubular necrosis. Surgical exploration and graft nephrectomy is indicated. The routine pretransplant crossmatch and verification of $\mathrm{ABO}$ compatibility between donor and recipient should prevent the majority of hyperacute rejection episodes [2].

\section{Accelerated Acute Rejection}

Accelerated acute rejection (or delayed hyperacute rejection)can occur within 24 hours to several days after transplant. It represents an anamnestic response by memory B and $\mathrm{T}$ cells from prior sensitization events, and may involve both humoral and cellular compoments. Even a negative crossmatch before transplant may not prevent the development of accelerated acute rejection, as the preformed DSA titer may be too low to be detected before kidney transplant [2].

\section{Acute Rejection}

Acute rejection can be either acute cellular rejection, antibody-mediated rejectionor both. It is more common

Table 1. Differential diagnosis of acute allograft dysfunction.

1. Pre-renal azotemia

Volume depletion (diuretics, poor intake, vomiting, diarrhea)

Vascular constriction (CNI toxicity, NSAID)

2. Intrinsic renal diseases

Arterial or venous stenosis, thrombosis or compression

ATN

Acute or accelerated acute rejection (cellular, humoral or both)

Pyelonephritis

Thrombotic microangiopathy (TMA)

Recurrent glomerular disease (FSGS, aHUS)

3. Post-renal obstruction

Foley catheter obstruction

Perinephris fluid collection (urine leak, hematoma, lymphocele)

Donor ureteral obstruction (kinking, stricture, blood clots)

Neurogenic bladder

Enlarged prostate (BPH, prostate cancer) 
and reversible than hyperacute rejection and accelerated acute rejection. The incidence of acute rejection has been steadily decreased over last two decades due to the wide use of antibody induction therapy and potent new immunosuppressive maintenance. Current acute rejection rate is about 10 percent within the first year after transplantation. Although the majority of acute rejection episodes occur in the first 3 to 6 months, but it can happen anytime in the lifetime of an allograft kidney [1] [2]. It may develop in a graft already suffering from delayed graft function (DGF) after transplant surgery. This can be difficult to be recognized if the patient clinically is anuric or oliguric [6] [7]. Therefore, any new graft with DGF should have serial biopsies to detect the covert development of rejection and be treated properly. The classic signs and symptoms of acute rejection may include low grade of fever, malaise, decreased urine output and graft tenderness. Urine analysis may show white blood cells and red blood cells. It is not uncommon for these patients to be misdiagnosed and treated as urinary tract infection at outside facility. However, the majority of patients do not have these classic signs and symptoms of acute rejection, instead, they only present as asymptomatic graft dysfunction as detected by laboratory monitoring. Kidney biopsy is necessary to make a definitive diagnosis of rejection. The use of noninvasive biomarkers in predicting and/or diagnosing acute rejection remains experimental. On the other hand, any patient presented with high grade fever, graft tenderness and systemic symptoms should be worked up and treated for infectious process immediately, such as pyelonephritis, wound infection, sepsis, CMV or fungal infection.

\section{Acute Cellular Rejection}

Acute cellular rejection (ACR) is diagnosed by histologic finding of T-lymphocyte infiltration in tubular-interstitial parenchyma (tubulitis) and vascular wall (arteritis). The Banff 2007 classification is the widely adoptedpathohistological definition of different types/grades of ACR [4]. Pulse corticosteroid is the first-line therapy for ACR in most centers. Methylprednisolone, 3 to $5 \mathrm{mg} / \mathrm{kg}$, is given intravenously for several (3 to 7) days. Mild or moderate ACR, such as Banff class borderline changes, $1 \mathrm{~A}$ or $1 \mathrm{~B}$, usually responds well to steroid pulse therapy. After intravenous pulse steroids, oral steroids are given and then tapered to a maintenance dosage [8] [9]. The maintenance immunosuppressive drugs may also need to be adjusted to prevent further ACR episode.

Steroid-resistant ACR was traditionally defined as lack of improvement in renal function within 5 to 7 days of intravenous pulse steroids. We consider those with progressively decreasing urine output or worsening renal function despite of 2 days of pulse corticosteroids as steroid resistance. In these cases, we start polyclonal antithymocyte globulin (ATG) early. Also, severe ACR with vascular involvement, such as Banff class 2A or above, often needs ATG therapy, as pulse steroids alone may not provide complete resolution of vascular rejection or recovery of renal function [10] [11]. There are two forms of ATG, either ATGAM or thymoglobulin. A direct comparison between thymoglobulin and ATGAM was performed, and thymoglobulin resulted in a higher rate of reversal of rejection and a lower rate of recurrent ACR [10]. The typical dose of thymoglobulin is either $3 \mathrm{mg} / \mathrm{kg}$ per day for 3 days or $1.5 \mathrm{mg} / \mathrm{kg}$ per day for 5 days. The FDA approved total dose of thymoglobulin for treatment of steroid resistant acute rejection is $10 \mathrm{mg} / \mathrm{kg}$. ATG is associated with severe side effects. The cytokine release syndrome can be prevented by concurrent administration of steroids, acetaminophen and diphenhydramine. Antiviral and antimicrobial prophylaxis against CMV infection and pneumocystis carinii pneumonia are recommended after ATG therapy [10] [11]. The risk of developing post transplant lymphoproliferative disease should be kept in mind, and patients should be monitored for this complication. Repeat kidney biopsy is indicated in ACR that is resistant to steroids and/or ATG to rule out other pathology, such as concurrent acute tubular necrosis, antibody-mediated rejection, BKV nephropathy or chronic irreversible fibrosis. The underline chronic fibrosis can be masked by interstitial inflammation of ACR, and it usually becomes more recognizable on repeat biopsy after the treatment of ACR.

\section{Antibody-Mediated Rejection}

Antibody-mediated rejection (AMR) was historically presumed when biopsy revealed severe vascular rejection or when the rejection was not responsive to the conventional treatment of ACR. The advent of C4d staining, sensitive assay to detect DSA and the description of typical histologic findings of AMR have improved our recognition that rejection is often AMR, either alone or in conjunction with ACR [2]-[5] [12] [13]. The Banff 2013 classification of AMR has been recently published [5]. Clinical diagnosis of AMR is usually based on 3 of the 4 criteria: 1). graft dysfunction; 2). detection of DSA; 3). positive C4d staining in the peritubular capillaries (PTC); and 4). the characteristic histologic findings, such as peritubularcapillaritis, glomerulitis and arterial fibroid ne- 
crosis. However, the risk of AMR is very high in pre-sensitized patients, such as HLA and/or ABO incompatible transplants after desensitization protocol, the husband to wife or the child to mother donation and the patients with known preformed DSA. In such high risk patients, AMR should be considered with fewer ( 2 of the 4$)$ diagnostic criteria in the absence of another identifiable cause of graft dysfunction, so that treatment may be initiated without delay [14].

DSA testing should be performed during the workup of graft dysfunction when AMR is concerned. Routine screening for the development of de novo DSA may permit early detection of AMR in high risk patients [15]. $\mathrm{C} 4 \mathrm{~d}$ is a degradation product of the classic complement pathway. A unique feature of $\mathrm{C} 4 \mathrm{~d}$ is that it binds covalently to the endothelial basement membrane, thereby avoiding removal during tissue processing. C4d deposition in PTC serves as an immunologic footprint of AMR. It is in a linear pattern and best demonstrated by immunofluorescence in frozen tissue section [3] [4] [12] [16]. But some patients with AMR may not have both positive DSA and C4d staining. Cases with positive DSA but negative C4d staining may result from either technique error (false negative), non-complement activating DSA, or low level of DSA detected by highly sensitive assay without clinical relevance [4] [13]. In addition, the production of DSA precedes C4d deposition in the course of AMR, and a biopsy performed too early may not find the typical C4d deposition. Also, AMR can be caused by non-HLA antibodies. These may include hemagglutinin A or B antibody, anti-MICA, anti-minor histocompatibility antigens (MiHA), antiendothelial antibodies and anti-angiotensin-2 receptor [2] [17] [18]. As our knowledge in transplant immunology advances, there will likely be more alloreactive and autoreactive antibodies to be discovered in the future.

Treatment of AMR is often refractory to the treatment used for ACR. The optimal therapy for AMR remains to be defined, but it usually consists of a combination of several modalities, such as plasmapheresis or immunoadsorption, IVIG, corticosteroids, rituximab, ATG, bortezomib, eculizumab and occasionally splenectomy [3] [19]-[25]. Plasmapheresis or immunoadsorption with protein A removes the circulating DSA, but neither can suppress antibody production [3] [19] [24]. AMR associated with high circulating DSA titer usually justify plasmapheresis or immunoadsorption as a part of its treatment. IVIG is often administrated after plasmapheresis. Possible actions of IVIG include anti-idiotypic antibodies neutralizing DSA, inhibiting complement binding or activation and suppressing DSA synthesis [3] [21] [25]. Rituximab depletes B cells and it has been used to treat AMR [3] [20] [21]. Corticosteroids and ATG remain beneficial as they can control the B cell response by depleting or inhibiting the helper T cells. Bortezomib activates apoptosis of plasma cells, therefore directly decreases DSA production [3] [21] [22]. Eculizumab is now being reported in managing AMR, especially the severe ones refractory to the conventional therapy [3] [21] [26]. Splenectomy has also been reported as a rescue treatment in patients with severe AMR not responding to other treatments [23]. DSA should be quantified and the trends are monitored to guide clinical treatment. Repeat kidney biopsies are frequently needed to assess the success of treatment and to rule out other concurrent pathologic processes, especially in those not response to a reasonable course of treatment.

Acute rejection is a predictor of developing chronic rejection and/or transplant glomerulopathy [3] [27]. An increase in proteinuria after rejection is associated with poor graft outcome. Early diagnosed and completely reversed rejection after treatment may not affect long-term graft survival [28]. Whenever a rejection is diagnosed and treated, it is important to address the possibility of non-compliance or inadequate immunosuppression. The failure to correct the contributing factor may increase the risk of recurrent rejection and/ or development of chronic rejection. Patient noncompliance with medications may be caused by their inability to tolerate the side effects or by the financial difficulty to afford drugs. Inadequate immunosuppression may also be caused by adding new drug or herbal supplement that induces cytochrome P-450 enzyme and increases the metabolism of calcineurin inhibitors and/or mTOR inhibitors, which leads to decline in the drug trough level [21]. Rescue therapy for refractory rejection is commonly based upon the administration of tacrolimus and/or mycophenolate to those not receiving them as maintenance prior to rejection episode [29] [30]. Other rescue modalities that may be considered include alemtuzumab [31] [32] and graft radiation [33].

\section{Subclinical Rejection}

Subclinical rejection is usually defined as histological evidence of acute rejection by protocol biopsies, but clinically patients have normal or stable graft function [34] [35]. Untreated subclinical rejection may be a precursor to chronic rejection [35]. However, treatment of subclinical rejection may not consistently prevent chronic rejec- 
tion and fibrosis lesions. It remains controversial whether protocol biopsy to diagnose subclinical rejection is necessary in all transplant patients. In many cases, it is difficult to separate a subclinical rejection from a normal graft accommodation. Therefore, protocol biopsy probably should be limited to high risk patients at current clinical practice [34] [36].

\section{Chronic Active AMR}

Chronic active AMR is diagnosed by combination of the typical chronic changes from biopsy (glomerular double counters, multilayering of PTC basement membrane, interstitial fibrosis/tubular atrophy (IF/TA), fibrous intimal thickening in arteries) and ongoing humoral activity (positive DSA, C4d staining in PTC, capillaritis) [3]-[5]. It is usually irreversible and there is no effective intervention for it [3] [37]. Theoretical treatment may include rituximab and/or IVIG to "control" the humoral activity or DSA level. The maintenance immunosuppressive drugs may be also increased or adjusted with more potent ones wishfully to "stabilize" the graft function. Arecent study of rituximab combined with triple maintenance of steroids, mycophenolate and calcineurin inhibitors provided encouraging results. Compared to the control group, rituximab group had partial therapeutic response and an improvement in medial renal graft survival [38]. Clearly, large clinical trials are needed to address this important issue.

\section{Chronic Allograft Dysfunction}

Chronic allograft dysfunction is a slow, progressive loss of renal function one or more years after kidney transplant, which was previously referred as chronic allograft nephropathy and now as interstitial fibrosis and tubular atrophy (IF/TA) in Banff classification [1]-[5]. Clinically, it is usually diagnosed by a slowly rising serum creatinine level, increasing proteinuria and worsening hypertension. IF/TA represents a complex process culminating immunological and non-immunological injuries. It is the second most common cause of graft loss after the leading cause, death with a functioning graft. Optimal treatment of IF/TA remains unknown. Other causes of chronic allograft dysfunction are summarized in Table 2. When a specific cause of graft dysfunction is identified, then appropriate treatment may improve or stabilize the graft function.

\section{New Biomarkers}

In addition to immunological risk analysis and screening for DSA, kidney biopsy is usually necessary for diagnosing allograft rejection. There has been great interest in searching for non-invasive biomarkers to predict acute rejection [39]-[44]. Several urine proteomics and biomarkers have been reported, such as CXCL9, CXCL 10, mRNA levels of grazyme B, perforin, TIM-3, FOXP3 and others [39]-[42]. Enhanced expression of perforin, granzyme B, Fas ligand, HLA class-1 antigens in peripheral blood leukocytes or tissue have been linked to rejection [43]-[45]. Recently, a three-gene signature of CD3E mRNA, IP-10 mRNA and 18S rRNA levels in urinary

Table 2. Differential diagnosis of chronic allograft dysfunction.

1. Immunological causes

Chronic active rejection (cellular, humoral or both)

Chronic rejection (cellular, humoral or both)

2. Non-immunological causes

Chronic CNI toxicity

Infection (BKV nephropathy, chronic pyeonephritis)

Chronic obstruction/ hydronephrosis

Recurrent or de novo glomerular diseases

Recurrent or de novo diabetic nephropathy

Hypertensive nephrosclerosis

Renal artery stenosis 
cells has been reported to be diagnostic and prognostic of acute cellular rejection in kidney transplant grafts [46]. Current available information remains inconclusive and better designed multicenter studies are required to validate these "rejection-specific" biomarkers for clinical practice [45].

\section{Conclusion}

Allograft rejection is an important and unique problem of graft dysfunction after kidney transplant. Hyperacute rejection is mediated by the preformed DSA, while accelerated acute rejection represents an anamnestic response by memory B and $\mathrm{T}$ cells due to prior sensitization. They occur early after transplant and may not be reversible. ACR is relatively more common and usually responds to pulse corticosteroids with or without ATG. The complexity of AMR as well as its detrimental effect has been increasingly recognized. The treatment acute AMR requires a combination of several modalities, such as plasmapheresis or immunoadsorption, IVIG, corticosteroids, rituximab and ATG. After successful treatment of acute rejection, the maintenance immunosuppressive drugs should be adjusted to prevent further acute rejection and/or evolution into chronic active rejection. Chronic rejection is usually not reversible and it has been recognized as the most important cause of chronic graft dysfunction and eventual graft failure.

\section{References}

[1] Zhang, R., Kumar, P., Ramcharan, T. and Reisin, E. (2004) Kidney Transplantation: The Evolving Challenges. The American Journal of the Medical Sciences, 328, 156-161. http://dx.doi.org/10.1097/00000441-200409000-00004

[2] Kumbala, D. and Zhang, R. (2013) The Essential Concept of Transplant Immunology for Clinical Practice. World Journal of Transplantation, 3, 113-118.

[3] Djamali, A., Kaufman, D.B., Ellis, T.M., Zhong, W., Matas, A. and Samaniego, A. (2014) Diagnosis and Mamagement of Antibody-Mediated Rejection: Current Status and Novel Approaches. American Journal of Transplantation, 14, 255-271. http://dx.doi.org/10.1111/ajt.12589

[4] Solez, K., Colvin, R.B., Racusen, L.C., Haas, M., Sis, B., Mengel, M., Halloran, P.F., Baldwin, W., Banfi, G., Collins, A.B., Cosio, F., David, D.S., Drachenberg, C., Einecke, G., Fogo, A.B., Gibson, I.W., Glotz, D., Iskandar, S.S., Kraus, E., Lerut, E., Mannon, R.B., Mihatsch, M., Nankivell, B.J., Nickeleit, V., Papadimitriou, J.C., Randhawa, P., Regele, H., Renaudin, K., Roberts, I., Seron, D., Smith, R.N. and Valente, M. (2008) Banff 07 Classification of Renal Allograft Pathology: Updates and Future Directions. American Journal of Transplantation, 8, 753-760. http://dx.doi.org/10.1111/j.1600-6143.2008.02159.x

[5] Haas, M., Sis, B., Racusen, L.C., Solez, K., Glotz, D., Colvin, R.B., Castro, M.C., David, D.S., David-Neto, E., Bagnasco, S.M., Cendales, L.C., Cornell, L.D., Demetris, A.J., Drachenberg, C.B., Farver, C.F., Farris 3rd, A.B., Gibson, I.W., Kraus, E., Liapis, H., Loupy, A., Nickeleit, V., Randhawa, P., Rodriguez, E.R., Rush, D., Smith, R.N., Tan, C.D., Wallace, W.D., Mengel, M. and Banff Meeting Report Writing Committee (2014) Banff 2013 Meeting Report: Inclusion of c4d-Negative Antibody-Mediated Rejection and Antibody-Associated Arterial Lesions. American Journal of Transplantation, 14, 272-283. http://dx.doi.org/10.1111/ajt.12590

[6] Saidi, R.F., Elias, N., Kawai, T., Hertl, M., Farrell, M.L. and Goes, N. (2007) Outcome of Kidney Transplantation Using Expanded Criteria Donors and Donation after Cardiac Death Kidneys: Realities and Costs. American Journal of Transplantation, 7, 2769-2774. http://dx.doi.org/10.1111/j.1600-6143.2007.01993.x

[7] Humar, A. and Matas, A.J. (2005) Surgical Complications after Kidney Transplantation. Seminars in Dialysis, 18, 505510. http://dx.doi.org/10.1111/j.1525-139X.2005.00097.x

[8] Shinn, C., Malhotra, D., Chan, L., Cosby, R.L. and Shapiro, J.I. (1999) Time Course of Response to Pulse Methylprednisolone Therapy in Renal Transplant Recipients with Acute Allograft Rejection. American Journal of Kidney Diseases, 34, 304-307. http://dx.doi.org/10.1016/S0272-6386(99)70359-8

[9] Gray, D., Shepherd, H., Daar, A., Oliver, D.O. and Morris, P.J. (1978) Oral versus Intravenous High-Dose Steroid Treatment of Renal Allograft Rejection. The Big Shot or Not? Lancet, 1, 117-118. http://dx.doi.org/10.1016/S0140-6736(78)90417-8

[10] Gaber, A.O., First, M.R., Tesi, R.J., Gaston, R.S., Mendez, R., Mulloy, L.L., et al. (1998) Results of the Double-Blind, Randomized, Multicenter, Phase III Clinical Trial of Thymoglobulin versus Atgam in the Treatment of Acute Graft Rejection Episodes after Renal Transplantation. Transplantation, 66, 29-37. http://dx.doi.org/10.1097/00007890-199807150-00005

[11] Webster, A.C., Pankhurst, T., Rinaldi, F., Chapman, J.R. and Craig, J.C. (2006) Monoclonal and Polyclonal Antibody Therapy for Treating Acute Rejection in Kidney Transplant Recipients: A Systematic Review of Randomized Trial Data. Transplantation, 81, 953-965. http://dx.doi.org/10.1097/01.tp.0000215178.72344.9d 
[12] Worthington, J.E., McEwen, A., McWilliam, L.J., Picton, M.L. and Martin, S. (2007) Association between C4d Staining in Renal Transplant Biopsies, Production of Donor-Specific HLA Antibodies, and Graft Outcome. Transplantation, 83, 398-403. http://dx.doi.org/10.1097/01.tp.0000251430.11723.b6

[13] Mengel, M., Sis, B., Haas, M., Colvin, R.B., Halloran, P.F., Racusen, L.C., et al. (2012) Banff 2011 Meeting Report: New Concepts in Antibody-Mediated Rejection. American Journal of Transplantation, 12, 563-570. http://dx.doi.org/10.1111/j.1600-6143.2011.03926.x

[14] Montgomery, R.A., Hardy, M.A., Jordan, S.C., Racusen, L.C., Ratner, L.E., Tyan, D.B. and Zachary, A.A. (2004) Consensus Opinion from the Antibody Working Group on the Diagnosis, Reporting, and Risk Assessment for Antibody-Mediated Rejection and Desensitization Protocols. Transplantation, 78, 181-185. http://dx.doi.org/10.1097/01.TP.0000129256.84027.D6

[15] Hidalgo, L.G., Campbell, P.M., Sis, B., Einecke, G., Mengel, M., Chang, J., Sellares, J., Reeve, J. and Halloran, P.F. (2009) De Novo Donor-Specific Antibody at the Time of Kidney Transplant Biopsy Associates with Microvascular Pathology and Late Graft Failure. American Journal of Transplantation, 9, 2532-2541. http://dx.doi.org/10.1111/j.1600-6143.2009.02800.x

[16] Troxell, M.L., Weintraub, L.A., Higgins, J.P. and Kambham, N. (2006) Comparison of C4d Immunostaining Methods in Renal Allograft Biopsies. Clinical Journal of the American Society of Nephrology, 1, 583-591. http://dx.doi.org/10.2215/CJN.00900805

[17] Hankey, K.G., Drachenberg, C.B., Papadimitriou, J.C., Klassen, D.K., Philosophe, B., Bartlett, S.T., Groh, V., Spies, T. and Mann, D.L. (2002) MIC Expression in Renal and Pancreatic Allografts. Transplantation, 73, 304-306. http://dx.doi.org/10.1097/00007890-200201270-00029

[18] Sun, Q., Cheng, Z., Cheng, D., Chen, J., Ji, S., Wen, J., et al. (2011) De Novo Development of Circulating Anti-Endothelial Cell Antibodies rather than Pre-Existing Antibodies Is Associated with Post-Transplant Allograft Rejection. Kidney International, 79, 655-662. http://dx.doi.org/10.1038/ki.2010.437

[19] Rocha, P.N., Butterly, D.W., Greenberg, A., Reddan, D.N., Tuttle-Newhall, J., Collins, B.H., et al. (2003) Beneficial Effect of Plasmapheresis and Intravenous Immunoglobulin on Renal Allograft Survival of Patients with Acute Humoral Rejection. Transplantation, 75, 1490-1495. http://dx.doi.org/10.1097/01.TP.0000060252.57111.AC

[20] Mulley, W.R., Hudson, F.J., Tait, B.D., Skene, A.M., Dowling, J.P., Kerr, P.G., et al. (2009) A Single Low-Fixed Dose of Rituximab to Salvage Renal Transplants from Refractory Antibody-Mediated Rejection. Transplantation, 87, 286289. http://dx.doi.org/10.1097/TP.0b013e31819389cc

[21] Zhang, R. (2013) Modern Immunosuppressive Therapy in Kidney Transplantation. Open Journal of Organ Transplant Surgery, 3, 22-31. http://dx.doi.org/10.4236/ojots.2013.32005

[22] Everly, M.J., Everly, J.J., Susskind, B., Brailey, P., Arend, L.J., Alloway, R.R., et al. (2008) Bortezomib Provides Effective Therapy for Antibody- and Cell-Mediated Acute Rejection. Transplantation, 86, 1754-1761. http://dx.doi.org/10.1097/TP.0b013e318190af83

[23] Locke, J.E., Zachary, A.A., Haas, M., Melancon, J.K., Warren, D.S., Simpkins, C.E., et al. (2007) The Utility of Splenectomy as Rescue Treatment for Severe Acute Antibody Mediated Rejection. American Journal of Transplantation, 7 , 842-846. http://dx.doi.org/10.1111/j.1600-6143.2006.01709.x

[24] Lorenz, M., Regele, H., Schillinger, M., Kletzmayr, J., Haidbauer, B., Derfler, K., et al. (2005) Peritransplantimmunoadsorption: A Strategy Enabling Transplantation in Highly Sensitized Crossmatch-Positive Cadaveric Kidney Allograft Recipients. Transplantation, 79, 696-701. http://dx.doi.org/10.1097/01.TP.0000148732.26761.FA

[25] Luke, P.P., Scantlebury, V.P., Jordan, M.L., Vivas, C.A., Hakala, T.R., Jain, A., et al. (2001) Reversal of Steroid- and Anti-Lymphocyte Antibody-Resistant Rejection Using Intravenous Immunoglobulin (IVIG) in Renal Transplant Recipients. Transplantation, 72, 419-422. http://dx.doi.org/10.1097/00007890-200108150-00010

[26] Locke, J.E., Magro, C.M., Singer, A.L., Segev, D.L., Haas, M., Hillel, A.T., et al. (2009) The Use of Antibody to Complement Protein C5 for Salvage Treatment of Severe Antibody-Mediated Rejection. American Journal of Transplantation, 9, 231-235. http://dx.doi.org/10.1111/j.1600-6143.2008.02451.x

[27] Opelz, G. and Dohler, B., Collaborative Transplant Study Report (2008) Influence of Time of Rejection on Long-Term Graft Survival in Renal Transplantation. Transplantation, 85, 661-666. http://dx.doi.org/10.1097/TP.0b013e3181661695

[28] Madden, R.L., Mulhern, J.G., Benedetto, B.J., O’Shea, M.H., Germain, M.J., Braden, G.L., et al. (2000) Completely Reversed Acute Rejection Is Not a Significant Risk Factor for the Development of Chronic Rejection in Renal Allograft Recipients. Transplant International, 13, 344-350. http://dx.doi.org/10.1111/j.1432-2277.2000.tb01008.x

[29] Woodle, E.S., Thistlethwaite, J.R., Gordon, J.H., Laskow, D., Deierhoi, M.H., Burdick, J., et al. (1996) A Multicenter Trial of FK506 (Tacrolimus) Therapy in Refractory Acute Renal Allograft Rejection: A Report of the Tacrolimus Kidney Transplantation Rescue Study Group. Transplantation, 62, 594-599. 
http://dx.doi.org/10.1097/00007890-199609150-00009

[30] Briggs, D., Dudley, C., Pattison, J., Pfeffer, P., Salmela, K., Rowe, P., et al. (2003) Effects of Immediate Switch from Cyclosporine Microemulsion to Tacrolimus at First Acute Rejection in Renal Allograft Recipients. Transplantation, 75 , 2058-2063. http://dx.doi.org/10.1097/01.TP.0000069041.48226.DD

[31] Clatworthy, M.R., Friend, P.J., Calne, R.Y., Rebello, P.R., Hale, G., Waldmann, H., et al. (2009) Alemtuzumab (CAMPATH-1H) for the Treatment of Acute Rejection in Kidney Transplant Recipients: Long-Term Follow-Up. Transplantation, 87, 1092-1095. http://dx.doi.org/10.1097/TP.0b013e31819d3353

[32] Csapo, Z., Benavides-Viveros, C., Podder, H., Pollard, V. and Kahan, B.D. (2005) Campath-1H as Rescue Therapy for the Treatment of Acute Rejection in Kidney Transplant Patients. Transplantation Proceedings, 37, 2032-2036. http://dx.doi.org/10.1016/j.transproceed.2005.03.042

[33] Wahl, A.O., Small Jr., W., Dixler, I., Strom, S., Rademaker, A., Leventhal, J., et al. (2006) Radiotherapy for Rejection of Renal Transplant Allografts Refractory to Medical Immunosuppression. American Journal of Clinical Oncology, 29, 551-554. http://dx.doi.org/10.1097/01.coc.0000231452.47998.88

[34] Rush, D., Arlen, D., Boucher, A., Busque, S., Cockfield, S.M., Girardin, C., et al. (2007) Lack of Benefit of Early Protocol Biopsies in Renal Transplant Patients Receiving TAC and MMF: A Randomized Study. American Journal of Transplantation, 7, 2538-2545. http://dx.doi.org/10.1111/j.1600-6143.2007.01979.x

[35] Seron, D. and Moreso, F. (2007) Protocol Biopsies in Renal Transplantation: Prognostic Value of Structural Monitoring. Kidney International, 72, 690-697. http://dx.doi.org/10.1038/sj.ki.5002396

[36] Nemeth, D., Ovens, J., Opelz, G., Sommerer, C., Dohler, B., Becker, L.E., et al. (2010) Does Borderline Kidney Allograft Rejection Always Require Treatment? Transplantation, 90, 427-432. http://dx.doi.org/10.1097/TP.0b013e3181e81b16

[37] Fehr, T. and Gaspert, A. (2012) Antibody-Mediated Kidney Allograft Rejection: Therapeutic Options and Their Experimental Rationale. Transplant International, 25, 623-632.

[38] Smith, R.N., Malik, F., Goes, N., et al. (2012) Partial Therapeutic Response to Rituximab for the Treatment of Chronic Alloantibody Mediated Rejection of Kidney Allografts. Transplant Immunology, 27, 107-113. http://dx.doi.org/10.1016/j.trim.2012.08.005

[39] Li, B., Hartono, C., Ding, R., Sharma, V.K., Ramaswamy, R., Qian, B., Serur, D., Mouradian, J., Schwartz, J.E. and Suthanthiran, M. (2001) Noninvasive Diagnosis of Renal-Allograft Rejection by Measurement of Messenger RNA for Perforin and Granzyme B in Urine. The New England Journal of Medicine, 344, 947-954. http://dx.doi.org/10.1056/NEJM200103293441301

[40] O'Riordan, E., Orlova, T.N., Mei, J.J., Butt, K., Chander, P.M., Rahman, S., Mya, M., Hu, R., Momin, J., Eng, E.W., Hampel, D.J., Hartman, B., Kretzler, M., Delaney, V. and Goligorsky, M.S. (2004) Bioinformatic Analysis of the Urine Proteome of Acute Allograft Rejection. Journal of the American Society of Nephrology, 15, 3240-3248. http://dx.doi.org/10.1097/01.ASN.0000145241.83482.68

[41] Renesto, P.G., Ponciano, V.C., Cenedeze, M.A., et al. (2007) High Expression of Tim-3 mRNA in Urinary Cells from Kidney Transplant Recipients with Acute Rejection. American Journal of Transplantation, 7, 1661-1666. http://dx.doi.org/10.1111/j.1600-6143.2007.01795.x

[42] Metzger, J., Chatzikyrkou, C., Broecker, V., Schiffer, E., Jaensch, L., Iphoefer, A., Mengel, M., Mullen, W., Mischak, H., Haller, H. and Gwinner, W. (2011) Diagnosis of Subclinical and Clinical Acute T-Cell-Mediated Rejection in Renal Transplant Patients by Urinary Proteome Analysis. Proteomics-Clinical Applications, 5, 322-333. http://dx.doi.org/10.1002/prca.201000153

[43] Heidt, S., San Segundo, D., Shankar, S., et al. (2011) Peripheral Blood Sampling for the Detection of Allograft Rejection: Biomarker Identification and Validation. Transplantation, 92, 1-9.

[44] Flechner, S.M., Kurian, S.M., Head, S.R., et al. (2004) Kidney Transplant Rejection and Tissue Injury by Gene Profiling of Biopsies and Peripheral Blood Lymphocytes. American Journal of Transplantation, 4, 1475-1479.

[45] Bestard, O., Cruzado, J.M., Franquesa, M.L. and Grinyo, J.M. (2010) Biomarkers in Renal Transplantation. Current Opinion in Organ Transplantation, 15, 467-473.

[46] Suthanthiran, M., Schwartz, J.E., Ding, R., et al. (2013) Urinary-Cell mRNA and Acute Cellular Rejection in Kidney Allografts. The New England Journal of Medicine, 369, 20-31. http://dx.doi.org/10.1097/TP.0b013e318218e978 